\title{
A Novel Approach on Thalidomide and their Analogues with their Therapeutic uses and Clinical Application
}

\author{
Rahul Singh Kushwaha', Pankaj Chasta², Aziz Ahmed², Dr. Kaushal K. Chandrol³ \\ 1Pharmacy Graduate, ${ }^{2}$ Assistant Professor and Researcher, ${ }^{3}$ Principal \\ 1,2,3Faculty of Pharmaceutical Sciences, Mewar University, Chittorgarh, Rajasthan, India
}

\begin{abstract}
How to cite this paper: Rahul Singh Kushwaha | Pankaj Chasta | Aziz Ahmed | Dr. Kaushal K. Chandrol "A Novel Approach on Thalidomide and their Analogues with their Therapeutic uses and Clinical Application" Published in International Journal of Trend in Scientific Research and Development (ijtsrd), ISSN: 24566470, Volume-3 | Issue-4, June 2019, pp.1022-1036, URL: https://www.ijtsrd.c om/papers/ijtsrd23 233.pdf

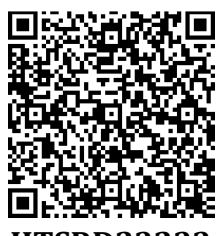
IITSRD23233
\end{abstract}

Copyright (C) 2019 by author(s) and International Journal of Trend in Scientific Research and Development Journal. This is an Open Access article distributed under the terms of the Creative Commons

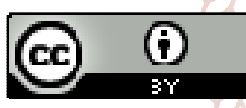
Attribution License (CC BY 4.0) (http: //creativecommons.org/licenses/by/4. $0)$

\section{INTRODUCTION}

Sarcomatous osteitis is a malignant multiplication of plasma cells that produce a monoclonalimmunoglobulin. Roughly 14,500 cases of MM will be analyed amid 2003 within the United States and spread harm in spite of the fact that treatable remains serious and account for $2 \%$ of cancer deaths[1]. While treatment may be conceded in the $20 \%$ of patients who are initially asymptomatic at diagnosis, the disease eventually progresses and all patients require systemic therapy. For decades discontinuous courses of alkylating agent (melphalan) and steroid (prednisone) have spoken to the standard chemotherapy for recently analyzed patients with symptomatic different myeloma. In spite of examination of numerous other medicate combination, counting those with different alkylating specialists, vinca alkaloids, and anthracyclines, basically all trails have failed to seem survival predominance up mephalan and prednisone[2]. Pulse dexamethasone-containing regimens, including VAD, [3] provide accelerated feedback, and taken after by myeloablative therapy with autogeneic stem cell support early in the disease, have resulted in modest gains for numerous patients. However, the disease eventually relapses in all patients and becomes opposition to treatment, accounting for the current median hold on of 3 to 5 years for symptomatic patients. For numerous a extended, it has been known that thalidomide has antiangiogenic belongings in vitro [4]. Critical vascularization has been illustrated within the marrowbone of patient with different myeloma especially in those with progressed malady[5,6]. Based on these highlight, in 1997 examiners at the Collage of Arkansas started a compassionate-use convention to survey the action of thalidomide in patients with end-stage numerous myeloma. One of 5 patients in this pilot study had a nearcomplete remission. This prompted a phase 2 trial of thalidomide, which confirmed significant activity of this agent in patients with progressive and refractory myeloma[7]. The action of thalidomide alone, counting in combination, has been confirmed by others, and this review will focus on thalidomide, its actions, and the results of clinical trials with this agent, as well as IMiDs, in multiple myeloma. In a continuation of our work on the structure activity relationship ,twenty-seven modern phthalimide subordinates were arranged to setup an suitable SAR. Our design was situated on the atomic hybridization of the phthalimide ring framework with a thiosemicarbazone, thiazolodinone or thiazole subunit (Figure: -1)[8]. 


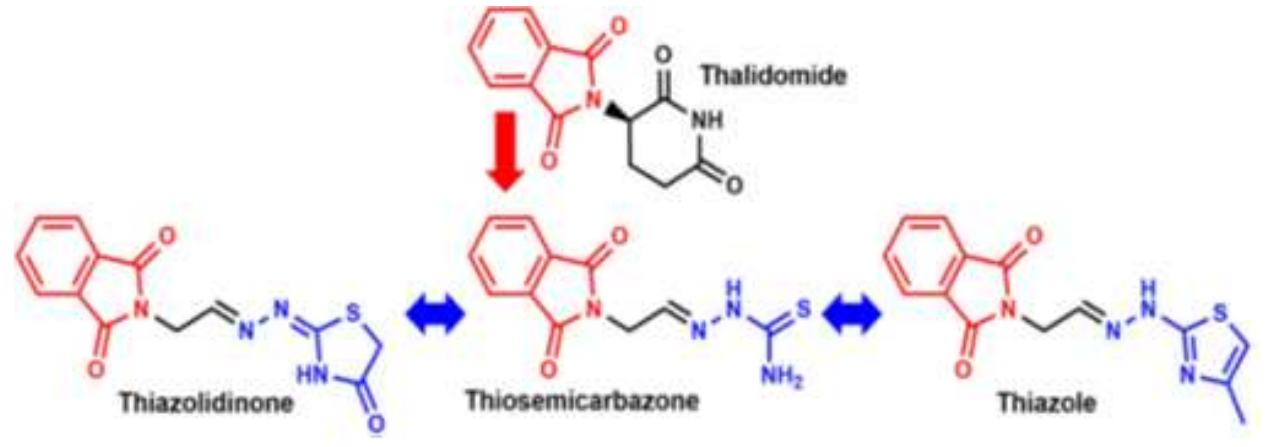

Figure: -1 Showing atomic hybridization of the phthalimide ring

\section{PHARMACOLOGY OF THALIDOMIDE AND ITS ANALOGS}

Thalidomide was initially utilised as non-sedative and in this way for the management of morning ailment within the 1950s. but was pulled back within the early 1960s since of visit teratogenicity (phocomelia)[9]. The medicate could be subordinate of glutamic corrosive the that comprises of a chiral centre and two amide ring, and it is categorised as an immunomodulatory specialist that moveover has antiangiogenic properties[10,11]. Thalidomide continue as a blend of both $\mathrm{R}$ and $\mathrm{S}$ isomers at physiologic $\mathrm{pH}$. While the $\mathrm{S}$ compound appears responsible for teratogenicity, the R compound results in sedation. At anatomy $\mathrm{pH}$ these isomers interconvert, making endevors at separation of the $\mathrm{R}$ isomer in an exertion to dispose of teratogenicity unsuccessful[11].

The mechanism of thalidomide's activity has been broadly examined about more than 50 a long time amid in that more than 30 speculations had been proposed $[12,13]$. Stephens and Fill more classified six theories of thalidomide, centering on variations or dysfunctions in: 1) DNA replication and translation, 2) amalgamation and/or work of development variables, 3) amalgamation and/or work of integrins, 4) angiogenesis, 5) chondrogenesis, and 6) cell passing or damage [13]. Among the six speculations displayed on thalidomide, most bolster has been given to its hostile to angiogenesis exercises.

Thalidomide is ineffectively dissolvable in water, and hence no intravenous arrangement is accessible. In vitro thalidomide has illustrated apoptoic IMiDs and anti-angiogenic impacts. It has been hypothesized that the antiangiogenic impacts of thalidomide are due to metabolites that hinder forms of angiogenesis intervened by bFGF and/or VEGF[4,14,15]. In expansion thalidomide represses TNF- alpha gene actuation by diminishing NF- alpha B binding[16]. Despite a previously demonstrated interaction between levels of marrow angiogenesis factors and disease activity in myeloma, and an increment within the angiogenic cytokines bFGF and VEGF in poor prognosis disease, no correlation between expanded microvascular density or subsequent post treatment decrease in neovascularization was noted in patients with disease responding to thalidomide[5$7,15,17,18]$. It appears unlikely that expanded of angiogenesis alone accounts for the success of thalidomide in controlling multiple myeloma.

It has been conformed in vitro such thalidomide and its acquaintance can directly inhibit growth of plasma cells, perhaps through caspase-8 dynamization and subsequent apoptosis[11,19]. Additionally,TNF-alpha not only stimulates pluripotent adult stem cell secretion of IL-6, but also induces look of adhesion molecules on myeloma and pluripotent grown-up stem cells[20,21].Since thalidomide may be a strong blocker of TNF- $\alpha$, the expression of these molecules on pluripotent grown-up stem cells may well be diminished by treatment, coming about in hindrance of myeloma cell attachment and diminised of TNF$\alpha$ stimulated IL-6 emission[22]. Thalidomide may too advance increment of fortified anti-CD3 T cells, which may increment inhibitory cytokines for myeloma cell development (intergalatic-alpha or IL-12)[23]. While the structure of growth inhibition by thalidomide remains unclear, there is an established apoptotic effect in vitro that is enhanced by dexamethasone. This effect may be partly conquered by IL-6, confirming the potential role of IL-6 suppression as a contributing antimyeloma effect of thalidomide[24].

\subsection{Lenalidomide (CC-5013)}

Lenalidomide (3-(7-amino-3-oxo-1H-isoindol-2-yl) piperidine-2,6-dione; Revlimid@) is an immunomodulatory analogue that has demonstrated higher potency than thalidomide in the HUVEC multiplicaion and tube creation assays. In vitro, the drug is up to $50 \mathrm{~K}$ times more strong than thalidomide inhibiting the management of TNF-a by fortified peripheral blood mononuclear cells[25]. Other in vitro studies marked that factors such as anti-angiogenic worth, modulation of host immunity, and apoptosis are likely to play a part in the clinical activity of lenalidomide, but the exact component of activity of the drug remains unclear[26] (Figure: -2). Lenalidomide also has a direct cytotoxic effect on myeloma cell lines. G0/G1 development capture shows up to be related in portion to refreshing of caspase 8 and down direction of hostile to apoptotic proteins such as the cIAP2 and FLIP[27,28]. Hindrance of lipopolysaccharide-mediated acceptance of COX-2 as well as PGE-2 union may moreover play a part within the drug's movement[29]. NF-kB is an essential regulator of cytokine management, myeloma cell adhesion and anti-apoptosis[30]. Lenalidomide, and other immunomodulatory drugs, inhibit and down-regulate NF-kB, which may interfere with cytokine-stimulated increase of MPC and subsequent adhesion to BMSCs[27]. A key manager of leukemia growth and continuity is IL-6[31]. Compared with BMSCs from patients without myeloma, BMSCs of victim with multiple myeloma release increased levels of IL-6, as well as bFGF and VEGF, which are integral to angiogenesis[31]. Lenalidomide decreases release of these factors in vitro, resulting in growth inhibition of myeloma cell channel and decreased micro vessel density in animal models. 


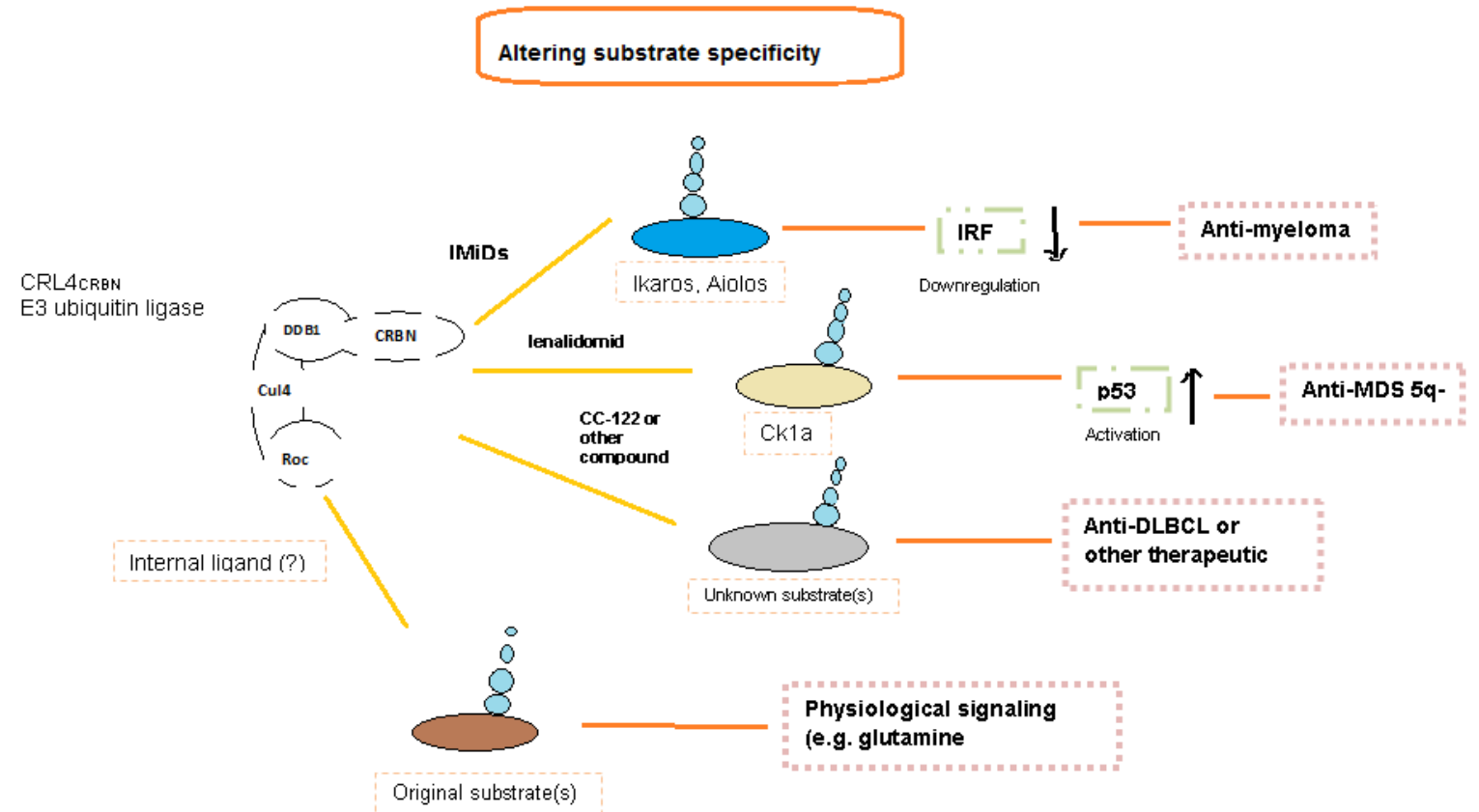

Figure: -2 Schematic representation of IMiDs-mediated CRBN balance. Within the non appearance of any IMiDs, CRBN debases unique substrates and have a certain part of physiological responses(e.g. glutamine system). Inner ligands of CRBN are conceivably included in this handle. On the other hand, within the nearness of an IMids, the substract specificity of CRBN is changed and neo-substrates are recognised and experience consequent protein degradation.

IMiDs(Lenalidomide) actuates the breakdown of Ikaros and Aiolos. Instep, unique substractes are collected. Lenalidomide particularly actuates the debasement $\mathrm{Ck} 1 \alpha$ by authoritative to CRBN.

\subsection{Pomalidomide (CC-4047)}

Pomalidomide is commercially known as Actimid® with IUPAC name; 4-amino-2-(2,6-dioxopiperidin-3-yl)isoindole-1,3-dione having clear immunomodulatory properties, represses numerous myeloma with obscure impacts on the human osteoclast heredity [32]. Early osteoclast forebears are of hematopoietic root and separate into develop bone resorbing multinucleated osteoclasts. Impacts of CC-4047 and thalidomide on human osteoclastogenesis were examined utilizing in vitro receptor actuate of NF $\alpha$-B ligand/MCS figure. The bone marrow societies were treated with CC-4047 for 3 weeks, displaying the diminished osteoclast arrangement went with by a total hindrance of bone resorption. A move of heredity commitment to granulocyte colony forming units was a calculate which intervened restraint of osteoclastogenesis by CC-4047. Treatment with thalidomide displayed a essentially less strong hindrance of osteoclast arrangement and bone resorption. The above-cited comes about appear that CC-4047 pieces osteoclast separation amid early stages of osteoclastogenesis. Subsequently, CC-4047 may be a profitable sedate for focusing on both tumors and osteoclastic action in patients with different myeloma and other illnesses related with osteolytic injuries.

\section{PHARMACOLOGICAL ACTIVITY OF THALIDOMIDE AND THEIR ANALOGUE}

\subsection{Anti-Cancer}

The most driving force for utilizing thalidomide to treat patients with cancer came with the revelation of its anti-angiogenic potential. This too happened to coincide with the emerging concept that treatment can be aimed at the framework that bolsters the development of the tumor, instead of focusing on tumor cells straight forwardly. Similitudes between the angiogenic handle within the advancement of tumor development and in inveterate irritation moreover loaned advance bolster for a conceivable part for thalidomide as an anti-inflammatory operator within the management of cancers. In specific the hostile to tnf impacts of thalidomide were thought to be pertinent as tnf appears to have a part in angiogenesis by upregulating the expression ofendothelial integrin, which is deciding for this process [33]. At long final, it is well built up that the increment of TNF- $\alpha$ within the serum of victim with cancer is frequently related with progressed illness, so utilizing thalidomide to decrease these levels might demonstrate to be useful within the medication of patients.

\subsection{Anti-Myeloma}

Thalidomide was serendipitously found to have against myeloma action when it was conclude its against angiogenic movement might passive the disease by repressing the formation of current blood vessels in this highly vascularized cancer. There's presently adequate prove to appear that the against cancer action of thalidomide and its analogs in numerous myeloma is through diverse components and locales in the marrowbone[34] (Figure: -3). It shows the marrowbone microenvironment in MM, which contains aberrations in various cellular processes, immunology, and cell interactions. Thalidomide and the IMiDs' immunomodulatory activities consist of inhibiting the interpretation of IL- 6 and TNF- $\alpha$ by BMSCs that in turn inhibit the growth of multiple myeloma cells. The compoundsalso improve t cell activate and multiplication with the enacted cells at that point discharging IL-2 and IFN- $\gamma$. These cytokines activate NK cells causing lysis of the multiple myeloma cells[34,35]. The combination of immunomodulatory and non-immunomodulatory anticancer exercises within the bone marrow is thought to deliver the significant anti-tumor reactions watched in a few numerous myeloma patients. This combination activity has significant implications for other blood and solid tumor cancers and is currently be inginvestigated in numerous clinical tests. 
Thalidomides are against incendiary and resistant modulatory drugs. They have been used in the management of multiple myeloma, pancreatic, prostate and lung cancers and also in autoimmune conditions such as unite versus have illness, Waldenstrom's macroglobulinaemia, and EAE, an mammalia model of MS.

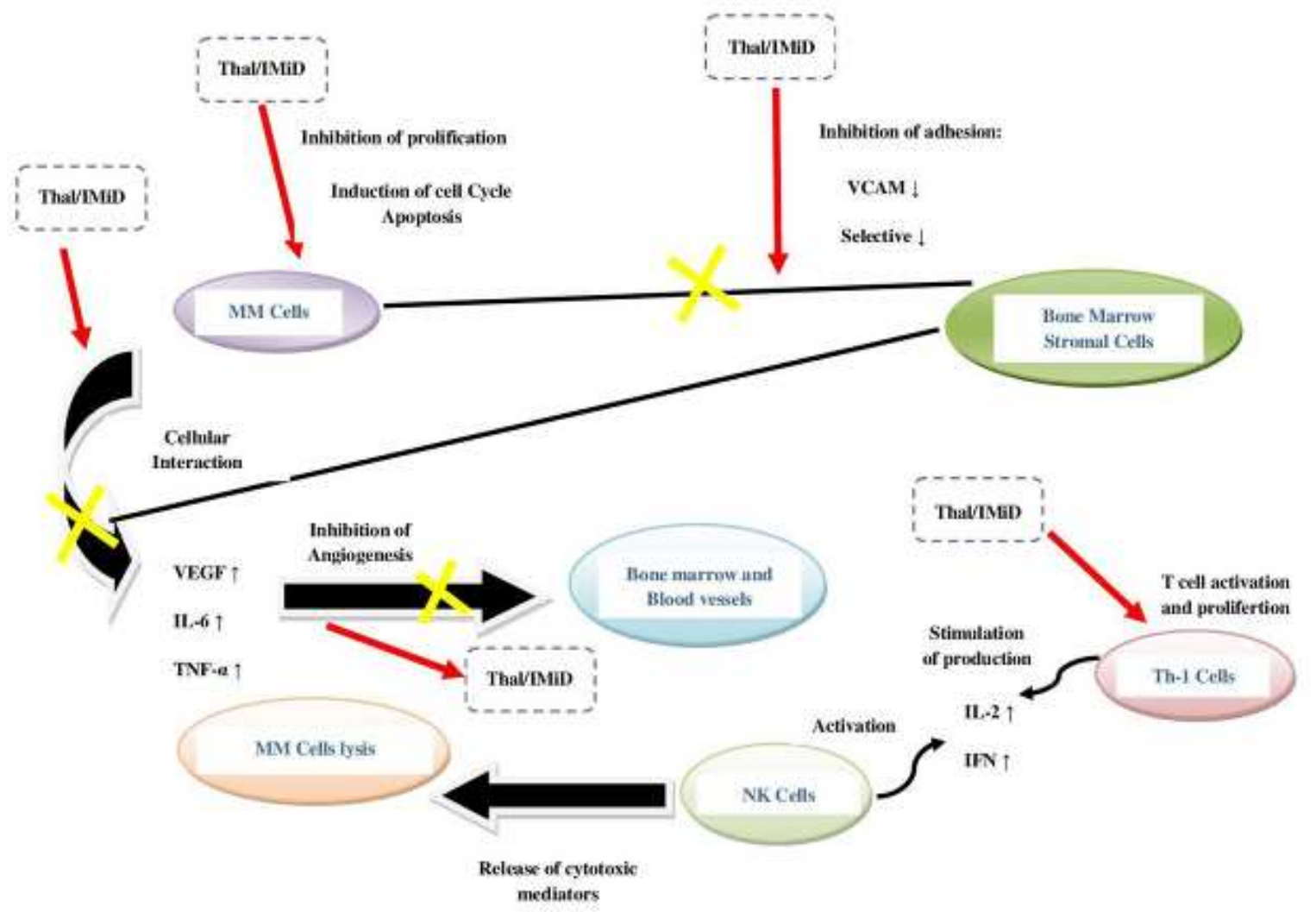

Figure: -3. Destinations of action of thalidomide and IMiDs within the bone marrow of different myeloma patients

\subsection{Anti-Angiogenesis}

The method of reasoning that recommends the potential of thalidomides in cancer treatment is that it can hinder cell multiplication, advance apoptosis and thus may control tumor development. By ideals of its capacity to restrain angiogenesis, it seem work as an anti-metastasis operator (Table: 1, Figure: -4). Numerous chemokines created by tumors can advance tumor development, actuate angiogenesis conjointly help with the avoidance of resistant observation. In this manner, it is of significant intrigued that thalidomides stifle these chemokines and combat the immunological brokenness related with tumors. The capacity to reestablish endogenous safe work has without a doubt been credited to the thalidomides. A few whereas prior, thalidomide was appeared to hinder VEGF and bFGF initiated angiogenesis in corneal angiogenesis [36,37]. Lenalidomide repressed VEGF induced P13K/Akt flagging and stifled the proangiogenic HIF-1. In vitro, it repressed tubule arrangement by endothelial cells. In vivo, there was much diminishment in lung colonisation of B16-10 murine melanoma[38]. Thalidomide and the analogs lenalidomide and pomalidomide repressed the in vitro transitory conduct of colorectal carcinoma cells. These drugs moreover smothered the arrangement of metastatic knobs in vivo murine has [39]. Angiogenesis is an necessarily handle within the pathogenesis and movement of incendiary and autoimmune diseases. MS could be a demyelinating infection ofthe central apprehensive framework. Angiogenesis may be a steady highlight of demyelinating plaques of MS. Numerous inducers of angiogenesis are communicated in these plaques and have been closely partnered in MS as well as within the creature demonstrate of MS viz. EAE. This has driven to the proposal that restraint of angiogenesis by smothering these effectors or restraining the components of angiogenic signaling pathways might give a reasonable way to target treatment to oversee MS [40].

Table: 1 Salient Biological Features Impacted by Thalidomides

\begin{tabular}{|c|c|}
\hline Biological Feature & Effector Targets \\
\hline Immune suppression; evasion of immune surveillance & Chemokines, ILs, TGF- $\beta$, VEGF \\
\hline Immunomodulation & CD41/CD81 T cells \\
\hline Immune resistance of tumours & Immune checkpoint proteins \\
\hline \multicolumn{2}{|l|}{ Tumour growth } \\
\hline Apoptosis & Bcl-2 \\
\hline Cell proliferation & Cell cycle regulators \\
\hline Invasion and metastasis & Cell adhesion signalling \\
\hline Angiogenesis & VEGF, bFGF \\
\hline
\end{tabular}




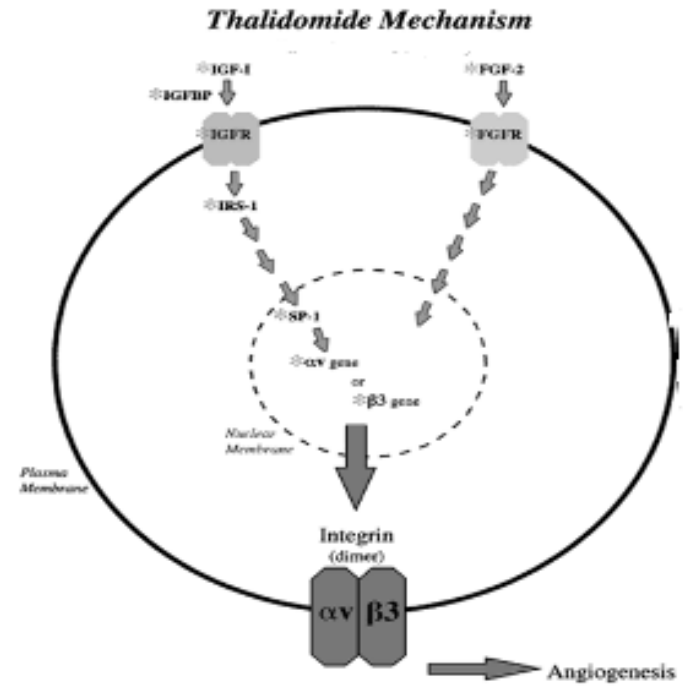

Figure: -4 Schematic representation of the IGF-I, FGF-2=Angiogenesis pathway within a model cell.

\subsection{Thalidomide inhibit cell proliferation and promote apoptosis}

The thalidomides suppress cell expansion by interferometer with cell cycle administrative components. Lenalidomide supressed CLL cells in vitro by focusing on cereblon[41]. Lenalidomide interceded inactivation of cereblon diminishes the acceptance of p21[42]. Cereblon could be a part of the ubiquitin_e3 ligase cul4_rbx1_ddb1 well-k nownand known to be particularly focused on by thalidomides [43]. Typically said to lead to the enrollment of zinc finger translation components to the ubiquitin_E3 complex, their ubiquitination and debasement smothering cell expansion and cell reasonability. NF- $\kappa \mathrm{B}$ is another pathway ensnared in thalidomide activity. Keifer illustrated this over a decade back[44]. Thalidomide repressed IKK and the NF- $\kappa B$ target qualities IL-8, TRAF1 and c-IAP2. Without a doubt, both thalidomide and lenalidomide square NF- $\kappa B$ enactment. The hindrance of NF- $\kappa B$ beside checked increment in Bax/Bcl-2 proportion which the impacts on the apoptosis family qualities were more checked than NF- $\kappa$ B restraint[45]. The mTOR flagging pathway is related with a few cellular forms such as cell expansion, development, apoptosis, angiogenesis, cell motility and intrusion (Figure: -5 and Table : -1 ). It seem encourage crosstalk between VEGF, PI3K/Akt and NF- $\mathrm{KB}$ in angiogenesis as implied to prior. The integration of these flagging systems by mTOR has driven to the recommendation that mTOR inhibitors may well be advantageously united with the thalidomide. This has been indicated by the cooperative energy seen within the impacts of everolimus and lenalidomide in a stage I clinical trial including hard-headed numerous myeloma patients. The combined treatment connected with the downregulation of mTOR signaling [46]. Temsirolimus has too been tried in combination with lenalidomide in another stage I trial in including patients with progressed shapes of cancer where a few reaction was watched with numerous tumor sorts[47]. Be that as it may, the last mentioned consider included as it were a little number of patients with each tumor sort. Ganesan displayed the middle generally survival and movement complimentary durability (PFS) of all evaluable patients. [47] They saw no reaction in HNSCC, NSCLC and endometrial carcinoma. This think about is as well preparatory in nature and there's a got to see at bigger number of patientsvwith particular tumor sorts where clinical reaction had been famous. It would be commendable of note here that plumbagin, a quinoid extricated from the origin of the Ceylon leadwort, has checked antitumour properties, which have been ascribed to its capacity to stifle the NF- $\kappa$ B/AKT/ mTOR/STAT3 flagging hub. Plumbagin allegedly complemented the acceptance of apoptosis by thalidomide, clearly by STAT3 concealment and enactment of the JNK apoptosis course [48]. So there's much defense for utilizing STAT3 inhibitors to diminish the successful measurement of thalidomide organization. Appropriation of a combination approach might assist decrease the potential disagreeable side impacts of thalidomide.

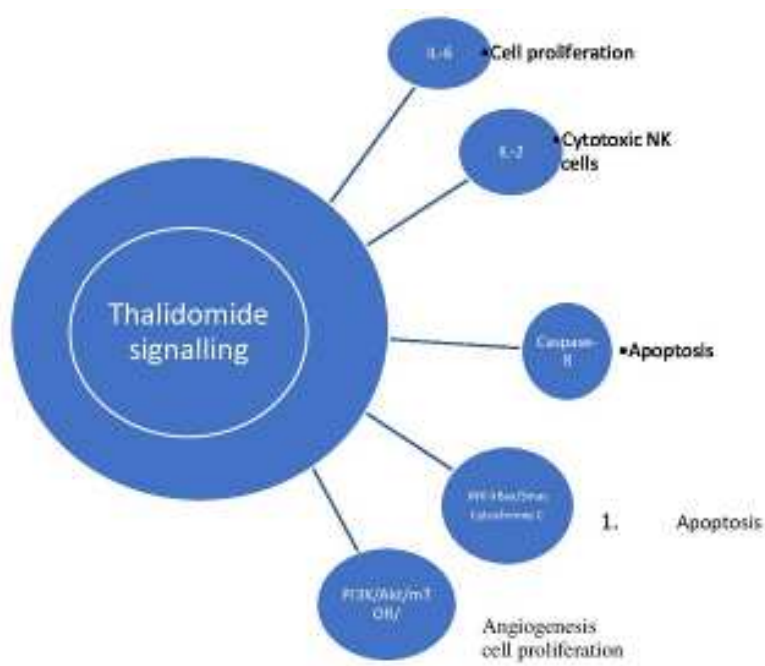

Figure: -5 Pathways of thalidomide signalling to control cell proliferation and induce apoptosis and inhibition of angiogenesis in myelomas and other tumours types. 


\subsection{Immunomodulation by Thalidomide}

Cancer improvement and movement happen as a result of the misfortune of reconnaissance inferable to a dynamic concealment of the safe framework. Tumors deliver safe suppressants such as ILs, TGF- $\beta$ and VEGF. Safe resilience of tumors more over comes about from the impedance of the separation and development of antigen-declare dendritic cells and the resulting impedances with the useful interaction with T- and B- lymphoblast and NK cells [49-51]. Techniques planned to invigorate the safe framework have been advancing over the past a few a long time. The improvement and arrangement of safe modulators aimed at safe checkpoints to re-activate endogenous resistant reactions have gotten much consideration. Safe resistance by tumors Immunomodulation by thalidomides appears to stream from tumors being able to embrace and disturb the resistant inhibitory checkpoint pathways, particularly pointed against T cells that are particular for tumor antigens(Figure: -6). Resistant checkpoint proteins adversely or emphatically control T-cell reaction. The cooperation between the receptor and ligand edge to the hindrance of T-cell enactment and cytokine generation. Balance of T-cell actuation pathways has taken the shape of utilizing antibodies against T-cell receptors or ligands. CTLA4 could be a checkpoint protein that smothers resistant reaction. PD-1 and its ligands are fundamental for the avoidance of resistant observation. These checkpoint proteins downregulate T-cell resistant reactions. Consequently, anti-CTLA4 and PD1 and its substance PDL1 are being assessed. As of late, Gorgun have appeared that lenalidomide complements the resistant impacts of PD1/PDL1 barricade in different myeloma. The heightened effects are interceded by cereblon, which could be a component of one of the hypothesized flagging frameworks locked in by resistant checkpoint inhibitors talked about in a afterward area[52]. The thalidomides can conflict the immune resistance of cancers, both hematological malignancies and strong tumors. The reaction of CD41 and CD81 cells from different myeloma patients to thalidomide analogs. Both drugs expanded expansion of and cytokine generation by cluster of differentiation 41 and cluster of differentiation 81 T cells, improved the lytic capacity of cytotoxic T lymphocytes and decreased the suppressive impacts of Treg (CD41 administrative T cells) on CD81 reactions [53]. Lenalidomide advanced the expansion of CD81 cells, but at that point it moreover improved a populace of myeloid cells, which were CD11/CD151. These cells were competent of stifling the multiplication of both CD81 and CD41. This had driven to the hypothesize that lenalidomide could be advancing both actuating and inhibitory components as a implies of controlling the safe framework [54]. One ought to review that target particular cd8 cells can be created to restrain angiogenesis. DNA immunizations focusing on VEGFR2 of the tumor vasculature have been appeared to repress tumor angiogenesis and both modern and built up metastatic stores [55]. Jellbauer may initiate CD81 cells by immunising creatures with a recombinant Salmonella strain carrying a CD8 epitope from VEGFR2 [56]. Within the B16-F10 melanoma tumor show, the vaccinated creatures appeared acceptance of VEGFR2-specific CD81 populace, which would have focused on the VEGFR2 communicating tumor vascular endothelium and diminished metastatic spread into the lungs and decreased tumor development. One can cite numerous occurrences of particular expression of development variables or their receptors in tumors, which can be targeted in this mold.
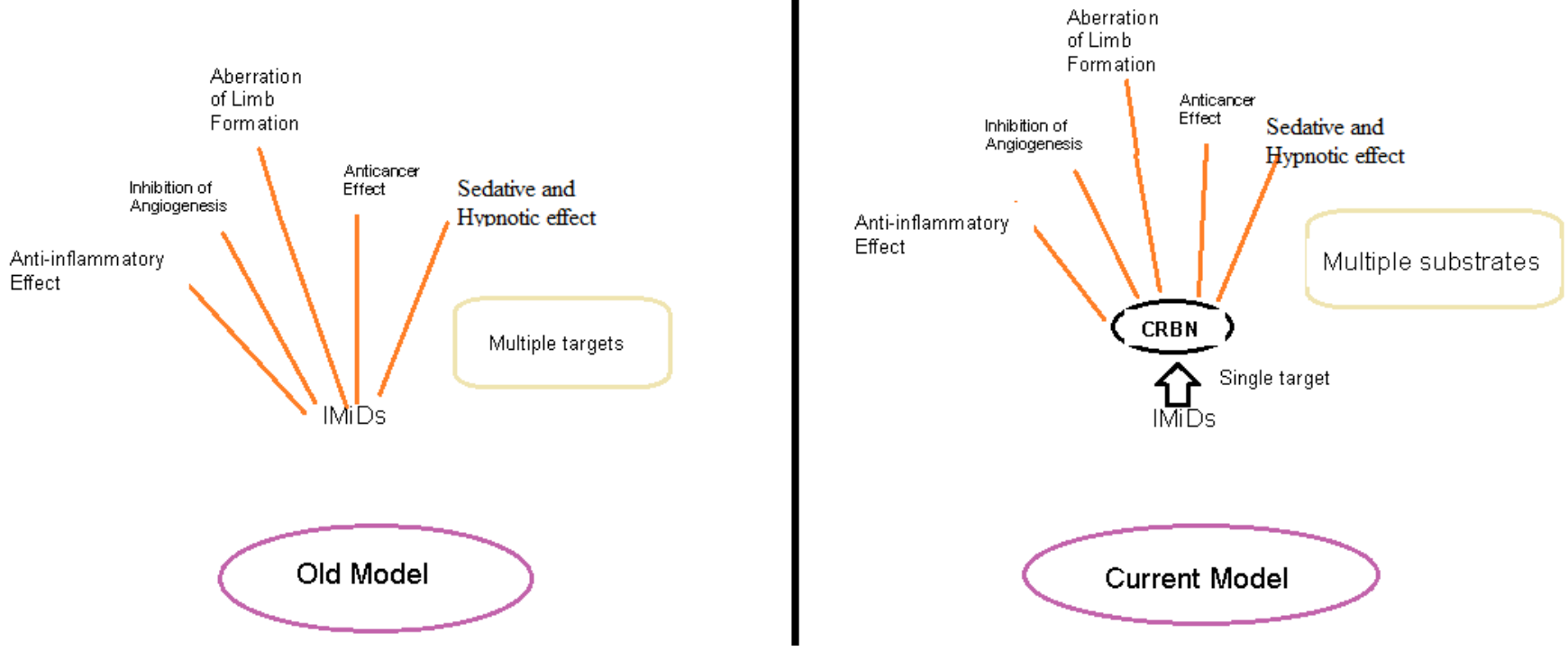

Figure: -6 Comparison between the classic demonstrate and the current demonstrate of the target of IMiDs. Within the ancient demonstrate, IMiDs have different coordinate targets resulting in pleiotropic impacts. Within the current demonstrate, IMiDs essentially ties CRBN, a essential targets, and initiate pleiotropic impacts by breakdown of different neo-substrates by CRBN E3 ubiquitin ligase.

\subsection{Anti-Leprosy}

ENL is an intense vasculitis seen in victim with lepromatous disease after antilepromatous management. It is distinguish by a excruciating, ulcerative, nodular rash and systemic indication such as hyperpyrexia, arthralgic, polyneuritis, and glomerular nephritis. Immunologically, it involves components of both a cell mediated immune feedback with raised IFN- $\gamma$, TNF- $\alpha$, and IL12 , and an immune complex mediated disease. Consequent to Sheskin's unique revelation a few controlled and uncontrolled considers, counting a World Wellbeing Association facilitated random shot composed trial, havebeen distributed affirming its viability[57]. More as of late a writing audit by Sheskin in 1980 dissected information from 4552 cases and found the reaction rate to treatment to be $99 \%$ [58]. Its effectiveness is thought to be due to its anticytokine impacts with responders appearing a checked diminishment in serum TNF- $\alpha$ levels in conjunction with down-regulation of intracellular attachment molecule- 1 and MHC course II antigen expression on epidermal keratinocytes[59]. Treatment can slowly be decreased after clinical reaction in spite of the fact that in numerous cases support moo measurements treatment is required for a number of years. 


\subsection{Anti-HIV infection}

Thalidomide has been observed to improve the wasting associated with AIDS and induce a better appetite [60-63]. The term "wasting syndrome" describes a clinical condition inwhich there is a greater than $10 \%$ weight loss without clear identifiable causes but believed to be related to a multifactorial process[64]. It is characterized by chronic diarrhea, weakness, and fever. These symptoms in an HIV sero positive individual set up the conclusion of AIDS and are an AIDS-related clinical disease [65]. Elevated levels of TNF-a are ensnared as a causal figure reticence of the synthesis of TNF-a in vitro and in vivo is the rationale for thalidomide's use in HIV positive individuals with wasting syndrome[66,67]. In a stray clinical studies of 28 adults with leading HIV disease, thalidomide (100 mg four times a day) was shown to impede the wasting syndrome and also improve the Karnofsky Scale of Performance Status [68]. There was no effect on the CD41T or viral load. There is also evidence that in victim with both HIV-1 and tuberculosis infections, there is a reduction of both the plasma TNF-a and HIV levels and a weight gain $[69,70]$. These observations propose that thalidomide may enhance weight gain by devaluation TNF-a and HIV-1 in patients who also have tuberculosis. Moreira have appeared that thalidomide and some analogs diminish HIV sort 1 duplicate in anthropoid macrophages[71]. AIDS-related Kaposi sarcoma has been reported to relapse when treated with thalidomide [72,73]. Thalidomide has too demonstrated exceptionally compelling within the treatment of weakening oropharynx, esophageal, rectal, and genital ulcers related with HIV disease [74-77]. Typically a valuable aide treatment, particularly when steroids are contraindicated or demonstrated incapable [78,79].

\subsection{Acute Myeloid Leukemia}

A as of late detailed trial of thalidomide in 16 patients with hard-headed or backslid AML appeared one total reaction enduring 36 months and a temporal diminishment in marrow impacts in two extra patients. There was no relationship between lessening in levels of angiogenesis and reaction. Hence, organization of thalidomide in AML isn't prescribed exterior the setting of clinical trials [80].

\section{ADVERSE DRUG REACTIONS OF THALIDOMIDE}

Thalidomide is well known for causing adverse reactions (ADRs) to the developing embryo. Since the discharge of the sedate it has been known that Thalidomide will cause fringe neuropathy in grown-ups on long term utilize [81]. This is especially seen in victim using Thalidomide for leprosy or multiple myeloma. It can also causes constipation, dizziness, skin rashes in some victim, and drowsiness. [82]. Caro reported about the ADRs caused by Thalidomide in multiple myeloma patients. In this study the frequency of ADR was 83.3\%. According to this study most common ADR was neurotoxicity (64.71\%), followed by blood disorders (17.64\%), edema (11.76\%) and digestive disorders (5.88\%). About half of the victims had extreme ADR and in almost $17.65 \%$ of cases were not settled [83]. It was detailed that ADRs of Thalidomide creates inside the primary month of treatment generally at a quantity of $400 \mathrm{mg} /$ day. Fringe neuropathy has been related with long term utilize of the medicate ( $>10$ months). The seriousness of the malady changed from gentle to direct. Common side impacts were dosage -dependent clogging, sedation, lower leg edema, dose-dependent dryness of mouth and skin, event of diseases, queasiness, spewing and fringe neuropathy $[84,85]$.

\section{NEW DEVELOPMENT AND THERAPEUTIC USES}

\subsection{Scope of nanomedicine as thalidomide pharmacotherapeutics}

Intravenous organization may well be an alternative way to form THD accessible to patients with impeded gastrointestinal work like ulcerations within the upper tract (HIV patients), destitute intestinal assimilation (GVHD) and coma. In any case, its moo watery dissolvability and moo steadiness impede the improvement of a parenteral detailing, which would be of clinical intrigued forthese patients [86-90] (Figure: -7). A few pharmaceutical procedures have been depicted to enhance steadiness and solvency of THD, such as its complexation with hydroxypropyl, cyclodextrin [91], the attempt to utilize the unadulterated enantiomeric shapes [92] with its affiliation to polymeric carriers[93]. Submicron emulsions, known as nanoemulsions, have been apply for a long time for parenteral sustenance and medicate conveyance due to their biocompatibility, relative soundness, capacity to solubilize tall amounts of hydrophobic compounds, capacity to decrease the poisonous quality of cytotoxic drugs and capacity to ensure drugs from hydrolysis and enzymatic degradation in physiologic conditions[94-97].

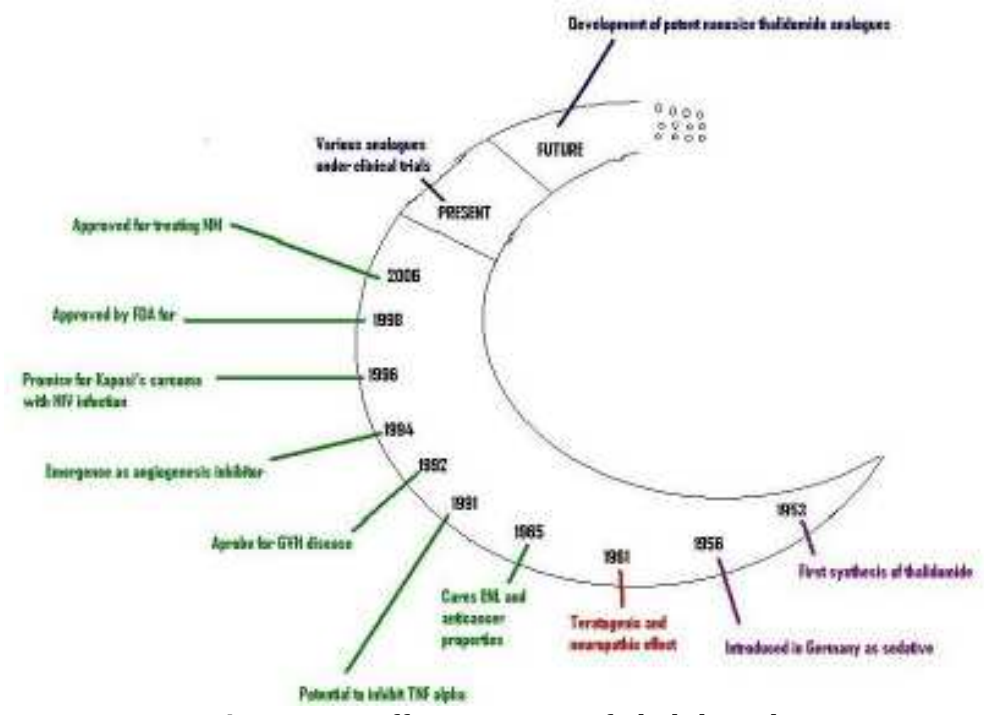

Figure: -7 Different stages of Thalidomide 


\subsection{THD nanoemulsions preparation}

The nanoemulsions were arranged by unconstrained emulsification[98,99]. Briefly, the natural stage comprising of outright ethanol, oil (castor oil, $10.0 \% \mathrm{w} / \mathrm{w}$ ), lipophilic emulsifier (soybean phosphatidylcholine, 3.0\%w/w) and THD (polymorphic frame) already homogenized, were infused into the watery stage comprising of water, osmotic specialist (glycerol, $2.25 \% \mathrm{w} / \mathrm{w}$ ) and a hydrophilic emulsifier (polysorbate 80), beneath attractive blending. The attractive blending was kept up amid $30 \mathrm{~min}$ to permit the framework to reach balance. The dissolvable extent was $1 / 2$, ethanol/water. Ethanol and abundance water were evacuated by evaporation beneath decreased weight until a volume of $10 \mathrm{~mL}$ was come to. The $\mathrm{pH}$ was balanced to $5.0-5.5$ with $\mathrm{HCl} 0.01 \mathrm{M}$. A to begin with set of details was arranged with diverse concentrations of thalidomide $(0.01,0.015,0.02$ and $0.05 \%$, $\mathrm{w} / \mathrm{w}$ ) and no hydrophilic emulsifier and named THD 0.01; THD 0.015; THD 0.02, and THD0.05, accordingly. A while later, another set of details was optimized with regard to the polysorbate 80 substance and named THD 0.01P0.5; THD 0.01P1.0; THD 0.01P2.0,and THD 0.01P4.0.

\subsection{Thalidomide research and cancer}

Dr. Jayesh Mehta (University of Arkansas) discussed preliminary results of research on the effects of thalidomide in treating multiple myeloma[100]. A study of 84 patients demonstrated that thalidomide showed antitumor activity in advanced and high-risk multiple myeloma, justifying its incorporation into combination chemotherapy trials. Dr. Jon Glass (New York University Hospital) presented an overview of research related to the use of thalidomide for brain tumors. Thalidomide has been appeared to alienate development figure initiated angiogenesis; it also reduces TNF-a production [101]. Potential effectiveness in the management of a number of neoplastic and inflammatory disorders has been suggested. Preparatory comes about of a study involving 71 victim with elementary brain tumors treated with thalidomide in sequence with carboplatin revealed a statistically Critical diminish within the microvascular thickness of these tumors compared with chemotherapy alone.

\subsection{REFRACTORY DISEASE}

\subsubsection{Single-Agent Thalidomide:}

Initially, Singhal reported a stage II trial of thalidomide in victim with advanced refractory MM[102]. Of the 84 patients studied, 76 had previous myeloablative therapy with stem cell support, although some were relapsing off therapy. Patients were treated with an starting dose of $200 \mathrm{mg}$ /day with dose escalation in $200 \mathrm{mg}$ increments every 2 weeks, in the absence of severe side effects, to a maximum of $800 \mathrm{mg} /$ day. The middle term of treatment was 80 days. Twenty-one patients (25\%) achieved par378 tial remission by criteria of $50 \%$ reduction in monoclonal protein. In a as of late distributed upgrade of that initial report, 169 patients were enrolled and $30 \%$ had at least a $50 \%$ reduction in paraprotein [103]. Two year occasion free and in general survival datas were $20 \%$ and $48 \%$, respectively, in this group of patients with advanced myeloma. Responding patients had a superior 2-year survival datas (69\%) compared with non responding patients (47\%). As expected, patients with normal cytogenetics, low plasma cell define list, and Beta- 2 microglobulin $<3 \mathrm{mg} / \mathrm{L}$ had a longer event-free survival.We confirmed a $25 \%$ response rate and projected middle reduction length of 15 months in a stage II study of 44 evaluable patients resistant to at least a pulse dexamethasone-containing regimen using criteriaof $\geq 50 \%$ and $\geq 75 \%$ reduction of serum and urine monoclonal paraprotein, respectively[104,105]. Many other trial shave confirmed this approximately $25 \%$ response rate of particular-agent thalidomide in refractory myeloma (Table: -2) [103-107,108-121]. It is essential to note that many thalidomide trials have used less stringent criteria (only $25 \%$ reduction or stable disease) for determining myeloma response compared to historical data where approx $50 \%$ decrease in monoclonal paraprotein has been required for partial remission.

Table: -2 Thalidomide in Resistant Myeloma: Selected Single-Agent and Combination Trials*

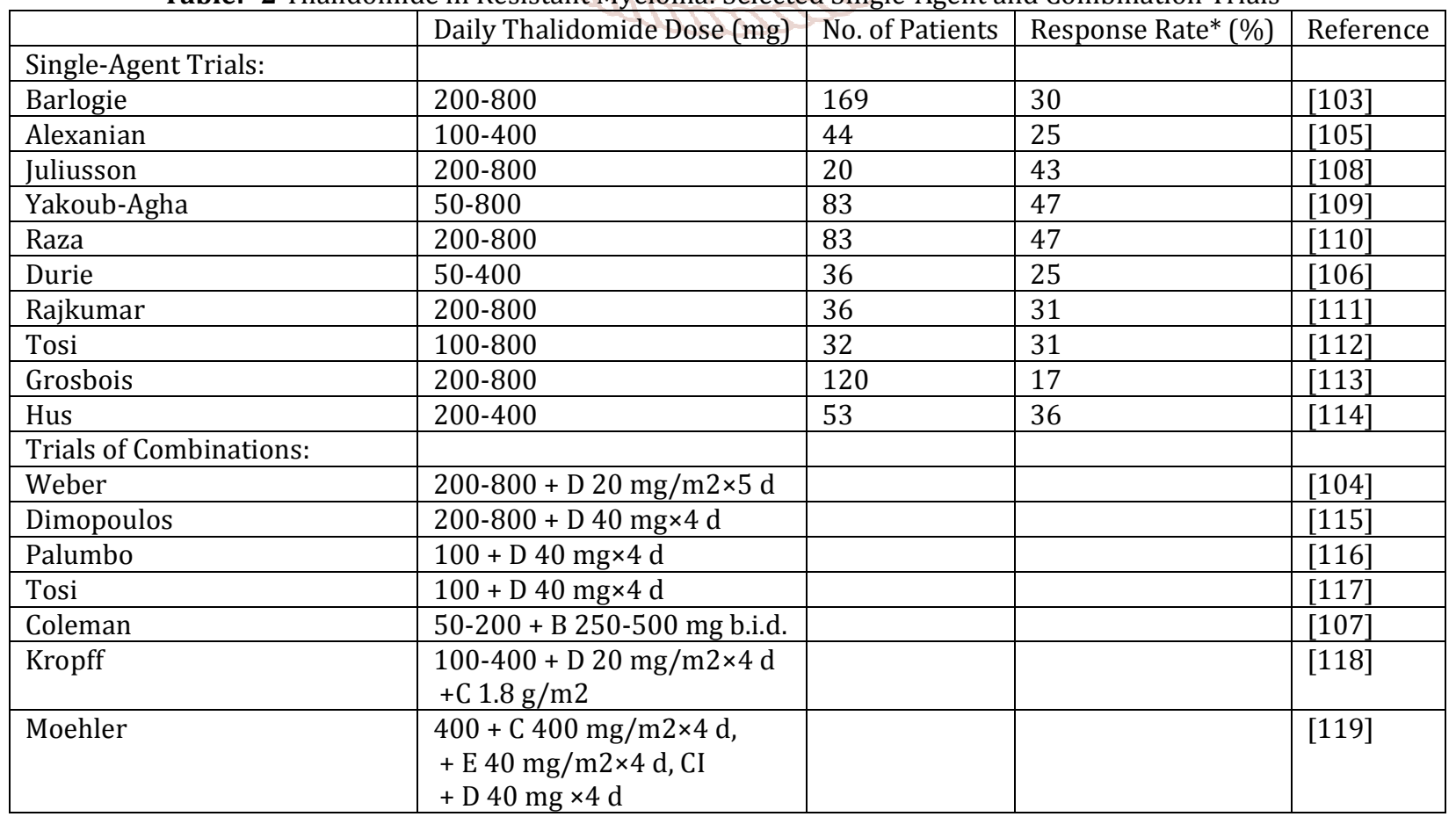


International Journal of Trend in Scientific Research and Development (IJTSRD) @ www.ijtsrd.com eISSN: 2456-6470

\begin{tabular}{|c|c|c|}
\hline Barlogie & $\begin{array}{l}400+\text { D } 40 \mathrm{mg} \times 4 \mathrm{~d} \\
+ \text { P } 10 \mathrm{mg} / \mathrm{m} 2 \times 4 \\
+ \text { A } 10 \mathrm{mg} / \mathrm{m} 2 \times 4 \mathrm{~d} \\
+ \text { C } 400 \mathrm{mg} / \mathrm{m} 2 \times 4 \mathrm{~d} \\
+ \text { E } 40 \mathrm{mg} / \mathrm{m} 2 \times 4 \mathrm{~d}\end{array}$ & [120] \\
\hline $\begin{array}{l}* \text { Studies with }>50 \% \text { M protein } \\
\text { reduction. } \\
D=\text { dexamethasone } \\
B=\text { clarithromycin (Biaxin) } \\
\mathrm{C}=\text { cyclophosphamide } \\
\mathrm{E}=\text { etoposide } \\
\mathrm{P}=\text { cisplatin } \\
\mathrm{A}=\text { doxorubicin } \\
\mathrm{CI} \text { = continuous infusion }\end{array}$ & & \\
\hline
\end{tabular}

Table: -3 IMiD-3 (CC-5013) for Relapsed/Refractory Multiple Myeloma (Response $\geq 50 \%$ Reduction in M Protein)

\begin{tabular}{|c|c|c|c|c|c|c|}
\hline \multirow{2}{*}{$\begin{array}{l}\text { Daily Dose } \\
\text { (mg) }\end{array}$} & \multicolumn{2}{|c|}{ Richardson [121] } & \multicolumn{2}{|c|}{ Zangari [122] } & \multicolumn{2}{|l|}{ Total } \\
\hline & $\begin{array}{l}\text { No. of } \\
\text { Patients }\end{array}$ & $\begin{array}{l}\text { No. of Responsive } \\
\text { Patients }\end{array}$ & $\begin{array}{l}\text { No. of } \\
\text { Patients }\end{array}$ & $\begin{array}{l}\text { No. of Responsive } \\
\text { Patients }\end{array}$ & $\begin{array}{l}\text { No. of } \\
\text { Patients }\end{array}$ & $\begin{array}{l}\text { No. of Responsive } \\
\text { Patients }\end{array}$ \\
\hline 5 & 6 & 1 & 3 & 0 & 9 & 1 \\
\hline 10 & 8 & 1 & 3 & 0 & 11 & 1 \\
\hline 25 & 6 & 6 & 3 & 1 & 9 & 1 \\
\hline 30 & 14 & 3 & 6 & 2 & 20 & 5 \\
\hline Total & $34^{*}$ & $5(26 \%)$ & 15 & $3(20 \%)$ & $49 * *$ & $8(23 \%)$ \\
\hline $\begin{array}{l}\text { *Number of } \\
\text { evaluable } \\
\text { patients: } 19\end{array}$ & & & & & & \\
\hline $\begin{array}{l}{ }^{* *} \text { Number of } \\
\text { evaluable } \\
\text { patients: } 34\end{array}$ & & & & & & \\
\hline
\end{tabular}

\subsubsection{Thalidomide in Combination With Other Agents:}

In 1999, we reported results of a trial of thalidomide (doses as previously described for single-agent thalidomide) in combo with intermittent pulse dexamethasone (dexamethasone $20 \mathrm{mg} / \mathrm{m} 2$ per day p.o. on days 1 to 5 and 15 to 19 repeated on approximately day 30, for a total of two courses, followed by maintenance on days 1 to 5 only, repeated every 4 weeks)[104,122]. In 47 patients with resistant myeloma, 22 patients (46\%) were resistant to both thalidomide and pulse dexamethasone given separately as single agents. The possibility of synergy between THD and dexamethasone was supported by the surprising response rate of $46 \%$ in patients safe to pair drugs given previously as single agents. This result was similar to the in general reaction rate of 52\%. A similar response rate of $55 \%$ in 44 patients with refractory myeloma was also reported by Dimopoulos[115]. Investigators at the collage of Arkansas are evaluating a program of DCEP in combination with thalidomide, compared with DCEP alone in patients with relapsing high-tumor-mass disease or with poor prognostic cytogenetics[120]. At a middle take after up of 17 months the reaction rate of $18 \%$, after 3 cycles of DCEP, doubled to $36 \%$ with the addition of thalidomide. The same group is investigating the DT-PACE procedure in patients with prior therapy vs intensive therapy with comparable stem cell transplantation. Among the first 179 patients treated with DT-PACE, only45\% were randomized, largely due to low frequency of response[120]. Eighty victims have been randomized and treated and are currently evaluable. Complete responses were noted in 26 of 39 patients who received tandem transplants and in only eleven of forty-one patients continuing on DT-PACE $(P=.0005)$. Two-year occasion free survival was similar at $73 \%$ in both arms, but 33 patients who failed DT-PACE went on to receive tandem transplant, making this result difficult to interpret. Because of the inferior results with continued DT-PACE, the study has been amended to include melphalan $100 \mathrm{mg} / \mathrm{m} 2$ with PBSC support in the DT-PACE arm. A study of VAD combined with thalidomide in refractory patients was terminated prematurely because of a high rate of thrombotic complications that were attributed to the combination of doxorubicin and dexamethasone[124,127](Table: -3$)$.

\subsection{PREVIOUSLY UNTREATED DISEASE}

\subsubsection{Single-Agent Thalidomide:}

Because of the significant action of thalidomide in refractory myeloma, we and others conducted trials in already untreated patients. Since the efficacy of thalidomide as a single agent was previously unknown, we figure out thalidomide $100-200 \mathrm{mg}$ per day escalating to $400 \mathrm{mg}$ everyday in patients with asymptomatic myeloma[123]. Twenty eight patients considered at tall hazard for early progression of disease (median 18 months), as determined by criteria we previously established, were included in this small trial. Partial remission, characterized by a $\geq 75 \%$ reduction in serum in protein synthesis and $\geq 95 \%$ reduction in urine Bence-Jones protein,was noted in 10 (36\%) of the 28 patients. Rajkumar conducted a comaprable trial noting a response datas of 38\% among 16 comparable patients[126,127]. Given the long period of illness stability for asymptomatic disease, any impact on time to progression or survival will take many years to determine. Since early management of asymptomatic victims with other agents has not previously improved survival, use of thalidomide in asymptomatic disease should be restricted to clinical trials until the benefits and long-term side impacts are established. 


\subsubsection{Thalidomide in Combination With Other Agents:}

The activity of THD and dexamethasone in refractory disease prompted several investigators to pursue this regimen in already untreated patients with symptomatic disease. Rajkumar reported 50 patients treated with $200 \mathrm{mg} /$ day of thalidomide with a dose escalation each 2 weeks up to $800 \mathrm{mg}$ /day along with $40 \mathrm{mg} /$ day of dexamethasone on odd cycles and days $1-4$ on indeed cycles[128]. Because 2 of the first 7 patients capable grade 3-4 skin toxicity, subsequent patients were treated with a fixed thalidomide dose of $200 \mathrm{mg} /$ day. 32 patients (64\%) had a $\geq 50 \%$ diminishment in serum $\mathrm{m}$ protein. Stem cell collect was completed without difficulty in 31 patients, and 26 patients proceeded to myeloablative treatment with stem cell support. In a similar trial at our center, 40 patients with untreated myeloma were given thalidomide 100-200 $\mathrm{mg}$ per day at bed time with acceleration up to $400 \mathrm{mg}$ [129]. Dexamethasone $20 \mathrm{mg} / \mathrm{m} 2$ everyday was given for 2 courses followed by dexamethasone on days 1 to 4 only for maintenance. Twenty nine patients (72\%) had a $\geq 75 \%$ diminishment in serum protein synthesis or $\geq 95 \%$ reduction in Bence-Jones proteinuria or both. Complete remission was noted in 7 patients (18\%). There was no difficulty in subsequent stem cell harvest for patients in whom this was attempted. Thalidomide is also currently being evaluated at the at the college of arkansas as part of induction for myeloablative therapy (total therapy III) [120] (Table: -4).

Table: -4 Selected Studies of Thalidomide in Patients With Untreated Myeloma

\begin{tabular}{|c|c|c|c|c|}
\hline Disease Status & $\begin{array}{l}\text { Thalidomide } \\
\text { Dose (mg) }\end{array}$ & $\begin{array}{l}\text { No. of } \\
\text { Patients }\end{array}$ & $\begin{array}{l}\text { Response } \\
\text { Rate* (\%) }\end{array}$ & Reference \\
\hline \multicolumn{5}{|l|}{ Asymptomatic: } \\
\hline Weber & $100-400$ & 28 & 36 & [123] \\
\hline Rajkumar & $200-800$ & 15 & 38 & [127] \\
\hline \multicolumn{5}{|l|}{ Symptomatic: } \\
\hline Rajkumar & $\begin{array}{l}200-400 \\
200^{* *}+D 40 \mathrm{mg} \\
4 \mathrm{~d}\end{array}$ & 50 & 64 & [128] \\
\hline Weber & $\begin{array}{l}100-400+\mathrm{D} 20 \\
\mathrm{mg} / \mathrm{m} 24 \mathrm{~d}\end{array}$ & 40 & 72 & [129] \\
\hline R & 2.00 & & & \\
\hline * Studies with $>50 \% \mathrm{M}$ protein reduction. & RU $=9$ & Q & & \\
\hline $\begin{array}{l}\text { ** Dose in the first } 7 \text { patients escalated up to } 400 \mathrm{mg} \text {. } \\
\text { Because of Stevens-Johnson syndrome in } 2 \text { patients, dose } \\
\text { was fixed at } 200 \mathrm{mg} \text { in the next } 43 \text { patients. }\end{array}$ & $\begin{array}{l}\text { al Journal } \\
\text { Scientific }\end{array}$ & & & \\
\hline $\mathrm{D}=$ dexamethasone & chalnd & 58 & & \\
\hline
\end{tabular}

\section{AUTHORIZED USES OF THALIDOMIDE}

In spite of the catastrophe related with the sedate, thalidomide and its subordinates are back on the show case for the treatment of particular conditions, counting certain leprosis complications and cancers, for which it speaks to an elective to calm patients. In most Western nations where it is authorized, get to to the sedate is entirely controlled and its utilize is confined to particular cases. Be that as it may, in numerous creating nations, sedate control is insufficient and babies proceed to be born with birth abandons, whereas it may well be maintained a strategic gap from.

\subsection{In Canada}

Since Admirable 4, 2010, the utilize of thalidomide (THALOMID $®$ ) is authorized in Canada for the management of patients matured 65 or more seasoned who endure from different myeloma, a sort of bone marrow cancer. Two thalidomide subordinates are moreover authorized: REVLIMID ${ }^{\circledR}$ and POMALYST $®$. Under the hone of medication a doctor can endorse this medicate for a condition other than different myeloma.Thalidomide is as it were accessible through a controlled dissemination program called RevAid $\AA$. The sedate is entirely contraindicated for pregnant ladies and ladies at hazard of getting to be pregnant. As it were program-certified doctors and drug stores are authorized to endorse thalidomide and patients that are utilizing it must be enrolled within the program.Before 2010, canadian doctors may have get to to thalidomide for the treatment of their patients, but only through Wellbeing Canada's Extraordinary Get to Program.

\subsection{In United States}

Since July 16, 1998, the Nourishment and Sedate Organization (FDA) of the Joined together States authorizes the utilize of thalidomide (THALOMID $®$ ) within the treatment of certain shapes of disease complications. Since Octobre 26, 2006, its utilize is additionally authorized in cases of numerous myeloma. Thalidomide is open on medicine as it were through a Chance Assessment and Moderation Methodology know as THALOMIDREMS $®$. The sedate is entirely contraindicated for pregnant ladies. For ladies of age to conceive, thalidomide can be endorsed, given that their doctor checks for pregnancy amid the treatment and illuminates the persistent satisfactorily. As it were doctors and drug specialists certified by the program are permitted to endorse and convey THALOMID $®$.

\section{CURRENT \& FUTURE DEVELOPMENTS}

The recovery of thalidomide which has however to be endorsed for different myeloma has expanded its exploratory utilize in various oncological and provocative conditions. The future of the more potent thalidomide analogs, particularly lenalidomide and pomalidomide, their immunomodulatory and anti-angiogenic potency and apparent lack of thalidomide's side effects, categorizing them as potentially important therapeutics in cancer, is very promising. The IMiDs represent 2G small molecules compounds with novel components of anti-cancer activity. Lenalidomide proceeds to be assessed within the treatment of a few unremitting immune system and auto inflammatory illnesses based on clinical advantage in different myeloma, 
due to anti-cytokine and against angiogenic properties. The continuous endeavors to move onward the harmfulness profile with understanding advance atomic targets will moreover offer assistance depict the neoplasms for which it may demonstrate clinical potency. Amalgamation of novel THD analogs like $\mathrm{N}$-substituted and tetrafluorinated classes of THD analogs, has been done with the proper understanding of IMiDs' metabolism. A few of these analogs have too appeared note worthy antitumor movement in preclinical prostate cancer xenotransplants models, which require further clinical investigation. The therapeutic impacts of CC-4047 have been assessed in various experimental models. The promising comes about seen in clinical studies of imids analogs of THD warrant proceeded clinical improvement of of the analogs and increased research efforts in distinguishing proof of potential targets in different neoplasms.

\section{CONCLUSION}

THD is an successful agent within the administration of MM. Although thalidomide is active, side effects that include constipation, fatigue, neuropathy, and thrombotic/ embolic complications may limit its use in some patients. Newer nonteratogenic derivatives, such as the IMiDs, are also effective but with a different spectrum of side effects, and experience remains limited. In the future, combinations of these specialists with novel components of activity (thalidomide, IMiDs, proteosome inhibitors, dexamethasone) followed by intensive therapy with stem cell support early in the disease should result in improved response rates, longer remissions, and improved survival for more patients.

\section{ACKNOWLEDGMENTS}

We thank Mr. Aziz Ahmed for his mentorship and Ms Deepika Thakur for editing and typing the manuscript.

\section{CONFLICT OF INTEREST}

The author(s) declare that they have no comflict of interest with respect to, authorship and publication of this article.

$\begin{array}{ll}\text { DCEC } & =\text { Dexamethasone, Cyclophosphamide, Etoposide, } \\ & \text { and Cisplatin } \\ \text { EAE } & =\text { Experimental Autoimmune Encephalomyelitis } \\ \text { MHC } & =\text { Major Histocompatibility Complex } \\ \text { MCS } & =\text { Macrophage Colony-Stimulating } \\ \text { STAT } & =\text { Signal Transducers and Activators of } \\ & \text { Transcription } \\ \text { CLL } & =\text { Chronic Lymphocytic Leukemia } \\ \text { JNK } & =\text { Jun N-Terminal Kinase } \\ \text { mTOR } & =\text { Mammalian Target of Rapamycin } \\ \text { PD-1 } & =\text { Programmed cell Death protein 1 } \\ \text { AIDS } & =\text { Acquired Immune Deficiency Syndrome } \\ \text { HIV } & =\text { Human Immunodeficiency Virus } \\ \text { AML } & =\text { Acute Myeloid Leukemia } \\ \text { ADRs } & =\text { Adverse Reactions } \\ \text { THD } & =\text { Thalidomide }\end{array}$

\section{LITERATURE CITED}

[1] Jamal A,Murray T, Samuels A, et al. Cancer statistics, 2003. CA Cancer J Clin. 2003; 53: 5-26.

[2] Combination chemotherapy versus melphalan plus prednisone as treatment for multiple myeloma: an overview of 6,633 patients from 27 randomized trials. Myeloma Trialist's Collaborative Group. J Clin Oncol. 1998; 16: 3832-3842.

[3] Barlogie B, Smith L, Alexanian R. Effective treatment of advanced multiple myeloma refractory to alkylating agents. N Engl J Med. 1984; 310: 1353-1356.

[4] D'Amato RJ, Loughran MS, Flynn E, et al. Thalidomide is an inhibitor of angiogenesis. Proc Natl Acad Sci U S A.1994; 91: 4082-4085.

[5] Vacca A, Ribatti D, Roncali L, et al. Bone marrow angiogenesis and progression in multiple myeloma. $\mathrm{BrJ}$ Haematol. 1994; 87: 503-508.

[6] Munshi N,Wilson CS. Increased bone marrow microvessel density in newly diagnosed multiple myeloma carries a poor prognosis. Semin Oncol.2001; 28: 565-569.

[7] Singhal S, Mehta J, Desikan R, et al. Antitumor activity of thalidomide in refractory multiple myeloma. $N$ EnglJ Med. 1999; 341: 1565-1571.

[8] A.I. Matesanz, P. Souza, a-N-heterocyclic thiosemicarbazone derivatives as potential antitumor agents: a structure-activity relationships approach, Mini Rev. Med. Chem. 9 (2009) 1389e1396, http: //dx.doi.org/10.2174/ 138955709789957422.

[9] Lenz W. Thalidomide and congenital anomalies. Lancet. 1962; 1: 45.

[10] Tseng S, Pak G, Washenik K, et al. Rediscovering thalidomide: a review of its mechanism of action, side effects, and potential uses. J Am Acad Dermatol. 1996; 35: $969-979$

[11] Stirling DI. Pharmacology of thalidomide. Semin Hematol. 2000, 37(1 suppl 3): 5-14.

[12] Stephens TD, Bunde CJ, Fillmore BJ. Mechanism of action in thalidomide teratogenesis. Biochem Pharmacol. 2000; 59(12): 1489-1499. [PubMed: 10799645]

[13] Stephens TD, Fillmore BJ. Hypothesis: thalidomide embryopathy-proposed mechanism of action. Teratology. 2000; 61(3): 189-195. [PubMed: 10661908] 
[14] Kenyon BM,Browne F, D'Amato R. Effects of thalidomide and related metabolites in a mouse corneal model of neovascularization. Exp Eye Res. 1997; 64: 971-978.

[15] Podar K,Tai YT, Davies FE, et al. Vascular endothelial growth factor triggers signaling cascades mediating multiple myeloma cell growth and migration. Blood. 2001; 98: 428-435.

[16] Turk BE, Jiang H, Liu JO. Binding of thalidomide to alpha 1- acid glycoprotein may be involved in its inhibition of tumor necrosis factor alpha production. Proc Natl Acad Sci U S A. 1996; 93: 7552-7556.

[17] Vacca A, Ribatti D, Presta M, et al. Bone marrow neovascularization, plasma cell angiogenic potential, and matrix metalloproteinase-2-secretion parallel progression of human multiple myeloma. Blood.1999; 93: 3064-3073.

[18] Bellamy W, Richter L, Frutiger Y, et al. Expression of vascular endothelial growth factor and its receptors in hematopoietic malignancies. Cancer Res. 1999; 59: 728-733.

[19] Mitsiades N, Mitsiades CS, Poulaki V, et al. Apoptotic signaling induced by immunomodulatory thalidomide analogs in human multiple myeloma cells: therapeutic implications. Blood. 2002; 99: 4525-4530.

[20] Richardson P, Hideshima T, Anderson K. Thalidomide: emerging role in cancer medicine. Annu Rev Med. 2002; 53: 629-657.

[21] Witzig TE. The role of adhesion receptors in the pathogenesis of multiple myeloma. Hematol Oncol Clin North Am. 1999; 13: 1127-1143.

[22] Sampaio EP, Sarno EN, Galilly R, et al. Thalidomide selectively inhibits tumor necrosis factor alpha production by stimulated human monocytes. J Exp Med. 1991; 173: 699-703.

[23] Davies FE, Raje N, Hideshima T, et al. Thalidomide and immunomodulatory derivatives augment natural killer cell cytotoxicity in multiple myeloma. Blood. 2001; 98: 210-216.

[24] Hideshima T, Chauhan D, Shima Y, et al. Thalidomide and its analogs overcome drug resistance of human multiple myeloma cells to conventional therapy. Blood. 2000; 96: 2943-2950.

[25] Muller GW, Chen R, Huang SY et al. Amino-substituted thalidomide analogs: potent inhibitors of TNFalpha production. Bioorganic \& Medicinal Chemistry Letters 1999 Jun 7; 9(11): 1625-1630.

[26] Anderson KC. Lenalidomide and thalidomide: mechanisms of action - similarities and differences. Seminars in Hematology 2005; 42(4 supplement 4): S3-S8.

[27] Mitsiades N, Mitsiades CS, Poulaki V et al. Apoptotic signaling induced by immunomodulatory thalidomide analogs in human multiple myeloma cells: therapeutic implications. Blood 2002; 99(12): 4525-4530.

[28] Mitsiades N, Mitsiades CS, Poulaki V et al. Apoptotic signaling induced by immunomodulatory thalidomide analogs in human multiple myeloma cells: therapeutic implications. Blood 2002; 99(12): 4525-4530.

[29] Fujita E, Jinbo A, Matuzaki $H$ et al. Akt phosphorylation site found in human caspase- 9 is absent in mouse caspase-9. Biochemical and Biophysical Research Communications 1999; 264(2): 550-555.

[30] Hideshima T, Chauhan D, Richardson P etal. NF-kappa $\mathrm{B}$ as a therapeutic target in multiple myeloma. Journal of Biological Chemistry 2002; 277(19): 16639-16647.

[31] Gupta D, Treon SP, Shima Y et al. Adherence of multiple myeloma cells to bone marrow stromal cells upregulates vascular endothelial growth factor secretion: therapeutic applications. Leukemia 2001; 15(12): 1950-1961.

[32] Anderson G, Gries M, Kurihara N, Honjo T, Anderson J, Donnenberg V, et al. Thalidomide derivative CC-4047 inhibits osteoclast formation by down-regulation of PU.1 Blood 2006; 107, 8,3098-105.

[33] Ruegg, C. et al. Evidence for the involvement of endothelial cell integrin ?V? 3 in the disruption of the tumour vasculature induced by TNF and IFN-?. Nature Med. 4, 408-414 (1998).

[34] Hideshima T, Chauhan D, Shima Y, et al. Thalidomide and its analog overcome drug resistance of human multiple myeloma cells to conventional therapy. Blood. 2000; 96: 2943-2950.

[35] Bartlett J, Dredge K, Dalgleish A. The evolution of thalidomide and its IMiD $\AA$ derivatives as anti-cancer agents. Nat Rev Cancer. 2004; 4: 314-322.

[36] D’Amato, R.J., Loughnan, M.S., Flynn, E., Folkman, J., 1994. Thalidomide is an inhibitor of angiogenesis. Proc. Natl Acad. Sci. USA 91, 4082_4085.

[37] Kenyon, B.M., Browne, F., D’Amato, R.J., 1997. Effects of thalidomide and related metabolites in a mouse corneal model of neovascularization. Exp. Eye Res. 64, 971_978.

[38] Lu, L., Payvandi, F., Wu, L., Zhang, L.H., Hariri, R.J., Man, H.W., et al., 2009. The anti-cancer drug lenalidomide inhibits angiogenesis and metastasis via multiple inhibitory effects on endothelial cell function in normoxic and hypoxic conditions. Microvasc. Res. 77, $78 \_86$.

[39] Liu, W.M., Henry, J.Y., Meyer, B., Bartlett, J.B., Dalgleish, A.G., Galustian, C., 2009. Inhibition of metastatic potential in colorectal carcinoma in vivo and in vitro using immunomodulatory drugs (IMiDs). Br. J. Cancer 101,803_812.

[40] Sherbet, G.V., 2015a. Do thalidomides have a role in the treatment of multiple sclerosis? Br. J. Med. Practitioners 8, a828.

[41] Fecteau, J.F., Corral, L.G., Ghia, E.M., Gaidarova, S., Futalan, D., Bharati, I.S., et al., 2014.

[42] Lenalidomide inhibits the proliferation of CLL cells via a cereblon/p21(WAF1/Cip1)-dependent mechanism independent of functional p53. Blood 124,1637_1644.

[43] Ito, T., Ando, H., Suzuki, T., Ogura, T., Hotta, K., Imamura, Y., 2010. Identification of a primary target of thalidomide teratogenicity. Science 327, 1345_1350.

[44] Keifer, J.A., Guttridge, D.C., Ashburner, B.P., Baldwin Jr., A.S., 2001. Inhibition of NF-kappa B activity by thalidomide through suppression of IkappaB kinase activity. J. Biol. Chem. 276,22382_22387.

[45] Liu, W.M., Strauss, S.J., Chaplin, T., Shahin, S., Propper, D.J., Young, B.D., et al., 2004. s-Thalidomide has a 
greater effect on apoptosis than angiogenesis in a multiple myeloma cellline. Hematol. J. 5, 247_254.

[46] Yee, A.J., Hari, P., Marcheselli, R., Mahindra, A.K., Cirstea, D.D., Scullen, T.A., et al., 2014. Outcomes in patients with relapsed or refractory multiple myeloma in a phase I study of everolimus in combination with lenalidomide. Br. J. Heamatol. 166, 401_409.

[47] Ganesan, P., Piha-Paul, S., Naing, A., Falchook, G., Wheler, J., et al., 2013. Phase I clinical trial of lenalidomide in combination with temsirolimus in patients with advanced cancer. Invest. New Drugs 31, 1505_1513.

[48] Sandur, S.K., Pandey, M.K., Sung, B., Aggarwal, B.B., 2010. 5-Hydroxy-2-methyl-1,4-naphthoquinone, a vitamin K3 analogue, suppresses STAT3 activation pathway through induction of protein tyrosine phosphatase, SHP-1: potential role in chemosensitization. Mol. Cancer Res.8, 107_118.

[49] Sarbassov, D.D., Ali, S.M., Kim, D.H., Guertin, D.A., Latek, R.R., Erdjument-Bromage, H., et al., 2006. Rictor, a novel binding partner of mTOR, defines a rapamycin-insensitive and raptorindependent pathway that regulates the cytoskeleton. Curr. Biol. 14, 1296_1302.

[50] Tan, L., Wei, X.P., Zheng, L.X., Zeng, J.C., Liu, H.B., Yang, S.J., 2016. Amplified HMGA2 promotes cell growth by regulating Akt pathway in AML. J. Cancer Res. Clin. Oncol. 142, 389_399.

[51] Yang, L., Carbone, D.P., 2004. Tumor host immune interactions and dendritic cell dysfunction. Adv. Cancer Res. 82, 13_27.

[52] Gorgun, G., Samur, M.K., Cowens, K.B., Paula, S., Bianchi, G., Anderson, J.E., et al., 2015. Lenalidomide enhances immune checkpoint blockade induced immune response in multiple myeloma. Clin. Cancer Res. Available from: $\underline{\mathrm{http}}$ : //dx.doi.org/10.1158/1078-0432.CCR-15-0200.

[53] De Keersmaecker, B., Fostier, K., Corthals, J., Wilgenhof, S., Heirman, C., Aerts, J.L., et al., 2014. Immunomodulatory drugs improve the immune environment for dendritic cell-based immunotherapy in multiple myeloma patients after autologous stem cell transplantation. Cancer Immunol. Immunother. 63, 1023_1036.

[54] Busch, A., Zeh, D., Janzen, V., Mugge, L.O., Wolf, D., Fingerhut, L., et al., 2014. Treatment with lenalidomide induces immunoactivating and counterregulatory immunosuppressive changes in myeloma patients. Clin. Exp. Immunol. 177, 439_453.

[55] Xiang, R., Luo, Y., Niethammer, A.G., Reisfeld, R.A., 2008. Oral DNA vaccines target the tumor vasculature and microenvironment and suppress tumor growth and metastasis. Immunol. Rev. 222, 117_128.

[56] Jellbauer, S., Panthel, K., Hetrodt, J.H., Rüssmann, H., 2012. CD8 T-cell induction against vascular endothelial growth factor receptor 2 by Salmonella for vaccination purposes against a murine melanoma. PLoS One 7, e34214.

[57] Iyer CG, Languillon J, Ramanujam K, et al. WHO coordinated short-term double- blind trial with thalidomide in the treatment of acute lepra reactions in male lepromatous patients. Bull World Health Organ 1971; 45: 719-32.

[58] Sheskin J. The treatment of lepra reaction in lepromatous leprosy. Fifteen years' experience with thalidomide. Int J Dermatol 1980; 19: 318-22.

[59] Sampaio EP, Hernandez MO, Carvalho DS, et al. Management of erythema nodosum leprosum by thalidomide: thalidomide analogues inhibit M. lepraeinduced TNFalpha production in vitro. Biomed Pharmacother 2002; 56: 13-19.

[60] Soler RA, Howard M, Brink NS, Gibb D, Tedder RS, Nadal D.1996b. Regression of AIDS-related Kaposi's sarcoma during therapy with thalidomide. Clin Infect Dis 23: 501-503.

[61] Weidle PJ. 1996. Thalidomide for aphthous ulcers in patients infected with the human immunodeficiency virus. Am J Health-Syst Pharm53: 368-378.

[62] Brown D. 1994. Once-reviled thalidomide shows promise as AIDS treatment.Washington Post, Science/Medicine, July 18, A3.

[63] Balog DL, Epstein ME, Amodio-Groton MI. 1998. HIV wasting syndrome: treatment update. Ann Pharmacother 32: 446-458.

[64] Centers for Disease Control and Prevention. 1993. Revised classification systems for HIV infection and expanded surveillance case definition for AIDS among adolescents and adults. MMWR 1992; 41: 1-19.

[65] Weinroth SE, Parenti DM, Simon GL. 1995. Wasting syndrome in AIDS: pathophysiologic mechanisms and therapeutic approaches. Infect Agents Dis 4: 76-94.

[66] Tracey KJ, Cerami A. 1994. Tumor necrosis factor: a pleiotropic cytokine and therapeutic target. Annu Rev Med 45: 491-503.

[67] Stirling DI. 1995. Potential use of thalidomide in HIV/AIDs. Am Rev Med Chem 30: 319-327.

[68] Reyes-Teran G, Sierra-Madero JG, Martinez del Cerro V, Arroyo- Figueroa H, Pasquetti A, Calva JJ, RuzPalacios GM. 1996. Effects of thalidomide on HIVassociated wasting syndrome: a randomized, doubleblind, placebo controlled clinical trial. AIDS, 10: 15011507.

[69] Tramontana JM, Utaipat U, Molloy A, Akarasew P, Burroughs M, Makonkawlreyoon S, Johnson B, Klausner JD, Rom W, Kaplan G. 1995. Thalidomide treatment reduces tumor necrosis factor alpha production and enhances weight gain in patients with pulmonary tuberculosis. Mol Med 1: 384-397.

[70] Klausner JD, Makonkawkeyoon S, Akarasewi P, Nakata K, Kasinerk W, Corral L, Dewar RL, Lane HC, Freedman VH, Kaplan G. 1996b.

[71] Moreira AL, Corral LG, Ye W, Johnson B, Stirling D, Muller GW, Freedman VH, Kaplan G.1997. Thalidomide and thalidomide analogs reduce HIV type 1 replication in human macrophages in vitro. AIDS Res Hum Retroviruses 13: 857-863.

[72] Soler RA, Howard M, Brink NS, Gibb D, Tedder RS, Nadal D.1996b. Regression of AIDS-related Kaposi's sarcoma during therapy with thalidomide. Clin Infect Dis 23: 501-503.

[73] Fife K, Howard MR, Gracie F, Phillips RH, Bower M. 1998. Activity of thalidomide in AIDS-related Kaposi's 
sarcoma and correlation with HHV8 titre. Int J STD AIDS 9: 751-755.

[74] Paterson DL, Georghiou PR, Allworth AM, Kemp RJ. 1995. Thalidomide as treatment of refractory aphthous ulceration related to human immunodeficiency virus infection. Clin Infect Dis 20: 250-254.

[75] Soler RA, Migliorati C,van Waes H, Nadal D.1996a. Thalidomide treatment of mucosal ulcerations in HIV infection. Arch Dis Child74: 64-65.

[76] Ball SC, Sepkowitz KA, Jacobs JL.1997. Thalidomide for treatment of oral aphthous ulcers in patients with human immunodeficiency virus: case report and review.Am J Gastroenterol 92: 169-170.

[77] Jacobson JM, Greenspan JS, Spritzler J, Ketter N, Fahey JL, Jackson JB, Fox L, Chernoff M,WuAW, MacPhail LA, Vasquez GJ, andWohl DA. 1997. Thalidomide for the treatment of oral aphthous ulcers in patients with human immunodeficiency virus infection. New Engl J Med 336: 1487-1493.

[78] Gardner-Medwin JMM, Smith NJ, Powell RJ. 1994. Clinical experience with thalidomide in the management of severe oral and gential ulceration in conditions such as Behcet's disease: use of neurophysiological studies to detect thalidomide neuropathy. Ann Rheum Dis 53: 828-832.

[79] Verberkmoes A, Boer K, Wertheim PME, Bronkhorst CM, Lange JMA.1996. Thalidomide for genital ulcer in HIV-positive woman. Lancet 347: 974.

[80] Thomas D, Estey E, Giles F, et al. Single agent thalidomide in patients with relapsed or refractory acute myeloid leukaemia. Brit J Haematol. 2003; 123(3): 436-441p.

[81] https: //www.drugbank.ca/drugs/DB01041

[82] Raina V, Sharma A, Anand M, et al. Use of simple hematological, biochemical and clinical parameters to monitor response of multiple myeloma patients on high dose thalidomide therapy. Indian J Cancer. 2005; 42(1): 46p.

[83] James H. Kim, Anthony R. Scialli, Thalidomide; The Tragedy of Birth Defects and the Effective Treatment of Disease, U S National Library of medicine National Institute of Health. Toxicol Sci. 2011; 122(1): 1-6p.

[84] Grover JK, Uppal G, Raina V. The adverse effects of thalidomide in relapsed and refractory patients of multiple myeloma. Ann Oncol. 2002; 13(10): 16361640p.

[85] Gramage Caro T, Orbe Izquierdo S, Perez Meneedezconde $\mathrm{C}$, et al. Adverse drug reactions in thalidomide treated patients, European Association of Hospital Pharmacists, 2008.

[86] Schmidt, H., Rush, B., Simonian, G., Murphy, T., Hsieh, J., Condon, M., 1996. Thalidomide inhibits TNF response and increases survival following endotoxin injection in rats. J. Surg. Res. 63, 143-146.

[87] Jacobson, J.M., Spritzler, J., Fox, L., Fahey, J.L., Jackson, J.B., Chernoff, M., Wohl, D.A., Wu, A.W., Hooton, T.M., Sha, B.E., Shikuma, C.M., MacPhail, L.A., Simpson, D.M., Trapnell, C.B., Basgoz, N., 1999. Thalidomide for the treatment of esophageal aphthous ulcers in patients with human immunodeficiency virus infection.
National Institute of Allergy and Infectious Disease Aids Clinical Trials Group. J.Infect. Dis. 180, 61-67.

[88] Eriksson, T., Bjorkman, S., Hoglund, P., 2001. Clinical pharmacology of thalidomide. Eur. J. Clin. Pharmacol. $57,365-376$.

[89] Teo, S.K., Colburn, W.A., Tracewell, W.G., Kook, K.A., Stirling, D.I., Jaworsky, M.S., Scheffler, M.A., Thomas, S.D., Laskin, O.L., 2004. Clinical pharmacokinetics of thalidomide. Clin. Pharm. 43, 311-327.

[90] Vogelsang, G.B., Higman, M.A., 2004. Chronic graft versus host disease. Br. J. Haematol.125, 435-454.

[91] Krenn, M., Gamcsik, M.P., Vogelsang, G.B., Colvin, O.M., Leong, K.W., 1992. Improvements in solubility and stability of thalidomide upon complexation with hydroxypropyl-_-cyclodextrin. J. Pharm. Sci. 81, 685689.

[92] Eriksson, T., Bjorkman, S., Roth, B., Hoglund, P., 2000. Intravenous formulations of the enantiomers of thalidomide: pharmacokinetic and initial pharmacodynamic characterization in man. J. Pharm. Pharmacol. 52, 807-817.

[93] Chen, H., Gu, Y., Hu, Y., 2008. Comparison of two polymeric carrier formulations for controlled release of hydrophilic and hydrophobic drugs. J. Mater. Sci.: Mater. Med. 19, 651-658.

[94] Benita, S., Levy, M.Y., 1993. Submicron emulsions as colloidal drug carriers for intravenous administration: comprehensive physicochemical characterization. J. Pharm. Sci. 82, 1069-1079.

[95] Klang, S., Benita, S., 1998. Design and evaluation of submicron emulsions as colloidal drug carriers for intravenous administration. In: Benita, S (Ed.), Submicron Emulsions in Drug Targeting and Delivery. Harwood Academic Publishers, Australia, pp. 119152.

[96] Han, J., Davis, S.S., Papandreou, C., Melia, C.D., Washington, C., 2004. Design and evaluation of an emulsion vehicle for paclitaxel. I. Physicochemical properties and plasma stability. Pharm. Res. 21, 15731580.

[97] Waitzberg, D.L., Torrinhas, R.S., Jacintho, T.M., 2006. New parenteral lipid emulsions for clinical use. J. Parenteral Enteral Nutr. 30, 351-367.

[98] Yu, W., Tabosa do Egito, E.S., Barratt, G., Fessi, H., Devissaguet, J.P., Puisieux, F., 1993. A novel approach to the preparation of injectable emulsions by a spontaneous emulsification process. Int. J. Pharm. 89, 139-146.

[99] Bouchemal, K., Briancon, S., Perrier, E., Fessi, H., 2004. Nano-emulsion formulation using spontaneous emulsification: solvent, oil and surfactant optimisation. Int. J. Pharm. 280, 241-251.

[100] Singhal S, Mehta J, Desikan R, Ayers D, Robertson P, Eddlemon P, Munshi N, Anaissie E, Wilson C, Dhodapkar M, Zeldis J, Barlogie B. 1999. Antitumor activity of thalidomide in refractory multiple myeloma. N Engl J Med 341: 1565-1571.

[101] Cao Z, Joseph WR, Browne WL, Mountjoy KG, Palmer BD, BaguleyBC, Ching LM. 1999. Thalidomide increases both intra-tumoural tumour necrosis factoralpha production and anti-tumour activity in response 
to 5,6-dimethylxanthenone-4-acetic acid. Br J Cancer 80: 716-723.

[102] Singhal S, Mehta J, Desikan R, et al. Antitumor activity of thalidomide in refractory multiple myeloma. $N$ Engl J Med. 1999; 341: 1565-1571.

[103] Barlogie B, Desikan R, Eddelmon P, et al. Extended survival in advanced and refractory multiple myeloma after single-agent thalidomide: identification of prognostic factors in a phase 2 study of 169 patients. Blood. 2001; 98: 492-494.

[104] Weber DM, Rankin K, Gavino M, et al. Thalidomide alone or with dexamethasone for previously untreated multiple myeloma. J Clin Oncol. 2003; 21: 16-19.

[105] Alexanian R,Weber D. Thalidomide for resistant and relapsing myeloma. Semin Hematol. 2000; 37(1 suppl 3): 22-25.

[106] Durie BGM, Stepan DE. Efficacy of low dose thalidomide (T) in multiple myeloma. Blood. 1999; 94(suppl 1): 316. Abstract.

[107] Coleman M, Leonard JP, Nahum K, et al. Nonmyelosuppressive therapy with BLT-D ([Biaxin], lowdose thalidomide, and dexamethasone) is highly active in Waldenström's macroglobulinemia and myeloma. Blood. 2000; 96: 167. Abstract.

[108] Juliusson G, Celsing F,Turesson I, et al. Frequent good partial remissions from thalidomide including best response ever in patients with advanced refractory and relapsed myeloma. Br J Haematol. 2000; 109: 8996.

[109] Yakoub-Agha I, Attal M, Dumontet C, et al. Thalidomide in patients with advanced multiple myeloma: a study of 83 patients. Report of the Intergroupe Francophone du Myelome (IFM). Hematol J. 2002; 3: 185-192.

[110] Raza SN,Veksler Y, Sabir T, et al. Durable response to thalidomide in relapsed/refractory multiple myeloma Blood. 2000; 96: 168. Abstract.

[111] Rajkumar SV, Fonseca R, Dispenzieri A, et al. A phase II trial of thalidomide in the treatment of relapsed multiple myeloma with laboratory correlative studies. Blood. 2000; 96: 168. Abstract.

[112] Tosi P, Ronconi S, Zamagni E, et al. Salvage therapy with thalidomide for patients with advanced relapsed/refractory multiple myeloma. Blood. 2000; 96: 296. Abstract.

[113] Grosbois B, Bellissant E,Moreau P, et al. Thalidomide (Thal) in the treatment of advanced multiple myeloma (MM): a prospective study of 120 patients. Blood. 2001: 98(pt 1): 689. Abstract.

[114] Hus M,Dmoszynska A,Soroka-Wojtaszko M,et al. Thalidomide treatment of resistant or relapsed multiple myeloma patients. Haematologica. 2001; 86: 404-408.

[115] Dimopoulos MA, Zervas K, Kouvatseas G, et al. Thalidomide and dexamethasone combination for refractory multiple myeloma. Ann Oncol. 2001; 12: 991-995.
[116] Palumbo A, Giaccone L, Bertola A, et al. Low-dose thalidomide plus dexamethasone is an effective salvage therapy for advanced myeloma. Haematologica. 2001; 86: 399-403.

[117] Tosi P, Zamagni E, Cellini C, et al. Rapid response and early relapse after thalidomide plus dexamethasone salvage therapy in patients with advanced and refractory multiple myeloma. Blood.2001; 98: 687. Abstract

[118] Kropff MH, Innig G, Mitterer $M$, et al. Hyperfractionated cyclophosphamide in combination with pulsed dexamethasone and thalidomide (HyperCDT) in primary refractory or relapsed multiple myeloma. Blood. 2000; 96: 725. Abstract.

[119] Moehler TM, Neben K, Benner A, et al. Salvage therapy for multiple myeloma with thalidomide and CED chemotherapy. Blood.2001; 98: 3846-3848.

[120] Barlogie B,Zangari M,Spencer T, et al. Thalidomide in the management of multiple myeloma. Semin Hematol. 2001; 38: 250-259.

[121] Richardson PG, Schlossman RL, Hideshima T, et al. A phase I study of oral CC5013, an Immunomodulatory thalidomide (thal) derivative, in patients with relapsed and refractory multiple myeloma (MM). Blood. 2001; 3225. Abstract

[122] Zangari M,Tricot G, Zeldis J, et al. Results of a phase I study of CC-5013 for the treatment of multiple myeloma (MM) patients who relapse after high dose chemotherapy (HDCT). Blood.2001; 3226. Abstract.

[123] Weber DM, Rankin K, Gavino M, et al. Thalidomide alone or with dexamethasone for previously untreated multiple myeloma. J Clin Oncol. 2003; 21: 16-19.

[124] Osman K, Comenzo R, Rajkumar SV. Deep venous thrombosis and thalidomide therapy for multiple myeloma. N Engl J Med. 2001; 25: 1951-1952.

[125] Zangari M, Siegel E, Barlogie B, et al. Thrombogenic activity of doxorubicin in myeloma patients receiving thalidomide: implications for therapy. Blood. 2002; 100: 1168-1171.

[126] Rajkumar SV, Hayman S, Fonseca R, et al. Thalidomide plus dexamethasone (Thal/dex) and thalidomide alone (Thal) as first line therapy for newly diagnosed myeloma (MM). Blood. 2000; 96: 168.Abstract.

[127] Rajkumar SV, Dispenzieri A, Fonseca R, et al. Thalidomide for previously untreated indolent or smoldering multiple myeloma. Leukemia. 2001; 15: 1274-1276.

[128] Rajkumar SV, Hayman SR, Gertz MA, et al. Combination therapy with thalidomide plus dexamethasone for newly diagnosed myeloma. J Clin Oncol. 2002; 20: 4319-4323.

[129] Weber DM, Rankin K, Delasalle K. et al. Thalidomide alone and in combination of previously untreated myeloma. Program and abstracts of the VIII International Myeloma Workshop, May 4-8, 2001, Banff, Alberta, Canada. Abstract S66. 